\title{
Primary Empty Sella Syndrome: A case Report
}

\author{
*Md. Sanwar Hossain ${ }^{1}$, Mahbuba Ashrafi Mumu², Md. Moyenuddin $\mathbf{P K}^{3}$ \\ ${ }^{1}$ Dr Md. Sanwar Hossain Associate Professor of Opthalmoloy, \\ Anwer Khan Modern Medical College \\ ${ }^{2}$ Miss Mahbuba Ashrafi Mumu, Junior Biochemist \\ Modern Diagnostic Center Limited, \\ ${ }^{3}$ Md. Moyeniddun PK, Biochemist, Modern Diagnostic Center Limited \\ *Corresponding Author
}

\begin{abstract}
Primary Empty Sella Syndrome (PES) is a relatively rare or uncommon developmental disease that develops spontaneously. It is characterized by herniation of subarachnoid space within the sella which is often associated with some degree of flattening of pituitary gland. Usually manifested by endocrine abnormalities, ocular abnormalities, rhinitis and intractable persistent headache. It is higher in obese females having multiple pregnancies. Here we report a case of empty sella syndrome in a 27 year old lady to aware the physicians to bear in mind a differential in patients having persistent intractable headache.
\end{abstract}

Key words: Empty Sella Syndrome, Woman, Obesity, Intractable Headache

\section{Introduction}

Empty sella syndrome (ESS) is a disorder that involves the sella turcica, a bony structure at the base of the brain that surrounds and protects the pituitary gland. ESS is a condition that is often discovered during tests for pituitary disorders, when radiological imaging of the pituitary gland reveals a sella turcica that appears to be empty ("partially empty sella") ${ }^{1}$. There are two types of ESS: primary and secondary. Primary ESS happens when a small anatomical defect above the pituitary gland increases pressure in the sella turcica and causes the gland to flatten out along the interior walls of the sella turcica cavity. Primary ESS is associated with obesity and high blood pressure in women. The disorder can be a sign of idiopathic intracranial hypertension. Secondary ESS is the result of the pituitary gland regressing within the cavity after an injury, surgery, or radiation therapy. Individuals with secondary ESS due to destruction of the pituitary gland have symptoms that reflect the loss of pituitary functions, such as the ceasing of menstrual periods, infertility, fatigue, and intolerance to stress and infection.

\section{Case Report}

A lady of 27 years came to us with the complaints of headache and geradual dimness of vision more in the right eye than the left since 1996. She also complaints of seeing small insect like images in the right visual field since then. The continuous dull aching pain in the right half of the scalp sometimes become so severe that she is forced to go to the neurologist to get relieve from unbearable pain. The neurologist prescribed some pain killers like Tablet Napro A and in this way she passed 15 years. The neurologist advice a CT scan of the brain and orbit.

\section{Investigations}

Occular examination reveal her visual aquity in the right eye is perception of light (PL) projection of rays (PR) present only. In the left eye $6 / 6$ with glass. On retinal examination $\mathrm{R} / \mathrm{E}$ shows pathological myopia with optic atrophy and the left eye is normal. Introccular pressure (IOP) in the right eye is $16 \mathrm{~mm}$ of $\mathrm{Hg}$ and left eye $14 \mathrm{~mm}$ of $\mathrm{Hg}$ measured by Applanation Tonometer. Her body weight is $55 \mathrm{~kg}$ and height 5 feet. The BMI is 20 . Her menstrual history was normal and the breast 
development was also normal. There was no history of galactorrhoea before first pregnancy. Her secondary sex characters were normal. She had three children, two daughters and one son.

Noncontrast CT scan of brain and orbit with 64 slice MSCT showed CSF density area is seen in sellar region compressing the pituitary gland suggesting empty sell. All other parameters of CNS were normal.

Hormone analysis: Her serum was analysed for hormone profile using a IMX Abbott USA Sysmex autoanalyser.The results showed increased serum TSH level 7. 31uIU/ml (normal 0.47-5.01uIU/ml) other hormone were normal like growth hormone level 5.18ng/ml (normal 1-10 ng.ml), prolactin $10.85 \mathrm{ng} / \mathrm{ml}$ (normall. 9-25. 9ng/ml) АCTH 27. $2 \mathrm{p} \mathrm{gm} / \mathrm{ml}$ (normal $5-60 \mathrm{pgm} / \mathrm{ml}$ ) LH $0.90 \mathrm{uIU} / \mathrm{ml}$, FSH $1.19 \mathrm{uIU} / \mathrm{ml}$.

On the above findings and clinical complaints a diagnosis of empty sella syndrome was made.

\section{Discussion}

Otolaryngologists frequently encounter patients with complaints of headaches. On occasion, normal physical examination findings may be accompanied by a roentgenographic enlargement of the sella turcica. In the process of evaluation for an intrasellar neoplasm, an "empty sella" is occasionally discovered. Patients with this condition commonly have headaches, although a cause-effect relationship is controversial. Endocrine and visual disturbances, although rare, necessitate periodic evaluation of these patients. In the present case the patient presented with persitent intractable headache and CT scan revealed an ESS.

Most of the studies found women preponderance in case of ESS. In one study in Italy between 19852002 observed 171 female and 42 male patients affected by PES (M:F ratio 4:1).The mean age of the subjects were $51.8 \pm 2$. 1 years. mean BMI $29.3 \pm 3.5$ $\left(\mathrm{kg} / \mathrm{m}^{2}\right)$. PES may be associated with variable clinical conditions ranging from mild endocrine abnormalities to severe intracranial hypertension, rhinorrhoea and persitant intractable headaches. Our case also is a woman and presented with persistent intractable headaches. However over case is 27 year woman. It is in contrast to the meanage of women in other studies which was $51.8 \pm 2$ yars. Another study reported a 58 year old woman with a history of hypothyroidism was evaluated for marked visual impairment and found to have the primary empty sella syndrome with multiple endocrine abnormalities. Visual field determination revealed preservation of vision only in the left inferior quadrants bilaterally. Failure of growth hormone (hGH), cortisol and prolactin to respond to insulin induced hypoglycaemia ( 0.1 $\mathrm{U} / \mathrm{kg}$ ), of luteinizing hormone ( $\mathrm{LH}$ ) and follicle stimulating hormone (FSH) to respond to gonadotrophin releasing hormone (GnRH, $100 \mu \mathrm{g}$ ) and of thyrotrophin (TSH) and prolactin to increase after thyrotrophin releasing hormone (TRH, $500 \mu \mathrm{g}$ ), confirmed the diagnosis of panhypopituitarism.

PES has also been reported in association with several endocrine autoimmune diseases, and PES itself has been suggested to be a consequence of lymphocytic hypophysitis suggesting that autoimmunity per se may not be significantly linked to the occurrence of PES. No autoimmunity was found in the present case.

On the other hand, pregnancy could promote the onset of PES In fact, the pituitary volume could double during pregnancy, particularly in the case of multiple pregnancies This may contribute to cause the herniation of subarachnoid space in case of hypoplastic diaphragma sellae and/or cerebrospinal fluid (CSF) hypertension, even if moderate and temporary. However ous case was not pregnant.

PES has been reported in a range between 5.5\% to $23 \%$ in autoptic excavation of the sella region and $8-35 \%$ of general population. PES is more frequent in females. The present case is a female.

PES has also been associated obesity. Morbid obesity can induce hypercapnia which can be the cause of chronic CSF pressure elevation and in turn may lead to, in subjects with hypoplasic diaphragma sellae, to the intracellar herniation of the suprasellar subarachnoid space. Our case is alsomildly obese. 


\section{Conclusions}

Any patient complaining of persistant headache, dimness of vision, obesity, endocrine abnormality must be investigated for empty sella syndrome. However if a young woman who only complaints of persistent headache and slight visual abnormality should also be investigated for ESS. This should be borne in mind of all clinicians and this will lead to early diagnosis and better management for the patient.

\section{References}

1. www.wikepedia.org/wiki/ Empty Sella Syundrome.

2. McLachlan MSF, Williams ED, Doyle FH 1968 Applied anatomy of the pituitary gland and fossa: a radiological and histopathological study based on 50 necropsies. $\mathrm{Br} J$ Radiol 41: 782-788.

3. Bergland RM, Ray BS, Torack RN 1968 Anatomical variations in the pituitary gland and adjacent structures in 225 human autopsy cases. J Neurosurg 28: 93-99.

4. Jordan RM, Kendall JW, Kerber CW 1977 The primary empty sella syndrome: analysis of the clinical characteristic, radiographic features, pituitary function and cerebral fluid adeno-hypophysial concentrations $\mathrm{Am}$ J Med 62: 569-580.

5 Bianconcini G, Bragagni G, Bianconcini M 1999 Primary empty sella syndrome. Observations on 71 cases. Recent Prog Med 90: 73-80.

6 Degli Uberti EC, Teodori V, Trasforini G, Tamarozzi R, Margotti A, Bianconi M, Rossi R, Ambrosio MR, Pansini R 1989 [The empty sella syndrome. Clinical radiological and endocrinologic analysis in 20 cases. Minerva Endocrinol 14: 1-18.
7 Becejac B, Vizner B, Berkovic M, Gnjidic Z, Vrklian M 2002 Neuroendocrinological aspects of primary empty sella. Coll Antropol. 26 (Suppl): 159-164.

8. Gallardo E, Schachter D, Caceres E, Becker P, Colin E, Martinez C, Henriquez C 1992 The empty sella: results of treatment in 76 successive cases and high frequency of endocrine and neurological disturbances. Clin Endocrinol (Oxf) 37: 529-533.

9. Giustina A, Bossoni S, Buffoli MG, Ferrari C, Pozzi A, Scalvini T, Schettino M 1992 Effect of pretreatment with pyridostigmine on the thyrotropin response to thyrotropin-releasing hormone in patients with Cushing's disease. Horm Metab Res 24: 248-250.

10. Giustina A, Bossoni S, Bodini C, Doga M, Girelli A, Buffoli MG, Schettino M, Wehrenberg WB 1991 The role of cholinergic tone in modulating the growth hormone response to growth hormone-releasing hormone in normal man. Metabolism 40: 519-523.

11. Giustina A, Veldhuis JD 1998 Pathophysiology of the neuroregulation of growth hormone secretion in experimental animals and the human. Endocr Rev 19: 717-797.

12. Giustina A, Scalvini T, Cerudelli B, Bossoni S, Bodini C, Orlandini A, Romanelli G 1989 [Hypopituitarism secondary to suprasellar giant carotido-ophthalmic aneurysm. Normalization of the hypophyseal function after neurosurgical depression of the aneurysm]. Minerva Endocrinol 14: 255-258.

13. Thomas R. Cupps and Paul D. Woolf Primary Empty Sella Syndrome with Pan hypopituitarism, Diabetes insipidus and visual field defects. Acta Endocrinologica; 89(3): 445-460. 